\title{
Mechanistic Studies on a Cu-Catalyzed Asymmetric Allylic Alkylation with Cyclic Racemic Starting Materials
}

\author{
Emeline Rideau, Hengzhi You, Mireia Sidera, Timothy D. W. Claridge,*() and Stephen P. Fletcher*(i) \\ Department of Chemistry, Chemistry Research Laboratory, University of Oxford, 12 Mansfield Road, Oxford, OX1 3TA, U.K. \\ Supporting Information
}

ABSTRACT: Mechanistic studies on Cu-catalyzed asymmetric additions of alkylzirconocene nucleophiles to racemic allylic halide electrophiles were conducted using a combination of isotopic labeling, NMR spectroscopy, kinetic modeling, structure-activity relationships, and new reaction development. Kinetic and dynamic NMR spectroscopic studies provided insight into the oligomeric $\mathrm{Cu}$-ligand complexes, which evolve during the course of the reaction to become faster and more highly enantioselective. The $\mathrm{Cu}$-counterions play a role in both selecting different pathways and in racemizing the starting material via formation of an allyl iodide intermediate. We quantify the rate of $\mathrm{Cu}$-catalyzed allyl iodide isomerization and identify a series of conditions under which

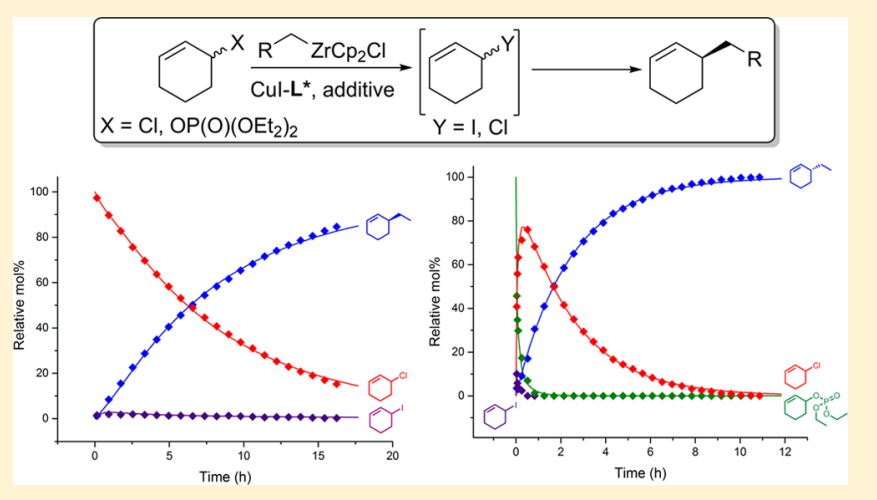
the formation and racemization of the allyl iodide occurs. We developed reaction conditions where racemic allylic phosphates are suitable substrates using new phosphoramidite ligand D. D also allows highly enantioselective addition to racemic sevenmembered-ring allyl chlorides for the first time. ${ }^{1} \mathrm{H}$ and ${ }^{2} \mathrm{H}$ NMR spectroscopy experiments on reactions using allylic phosphates showed the importance of allyl chloride intermediates, which form either by the action of TMSCl or from an adventitious chloride source. Overall these studies support a mechanism where complex oligomeric catalysts both racemize the starting material and select one enantiomer for a highly enantioselective reaction. It is anticipated that this work will enable extension of copper-catalyzed asymmetric reactions and provide understanding on how to develop dynamic kinetic asymmetric transformations more broadly.

\section{INTRODUCTION}

Copper is highly valued in synthetic organic chemistry, and a great number of asymmetric $\mathrm{Cu}$-catalyzed methods have recently been developed. ${ }^{1-4}$ However, the mechanisms and structures of organocopper species involved in asymmetric addition reactions are poorly understood ${ }^{5,6}$ despite extensive studies on nonstereoselective processes. ${ }^{6}$

In the past decades, asymmetric allylic alkylation (AAA) reactions have emerged as powerful tools ${ }^{7-12}$ that may accommodate both achiral and chiral substrates. Enantioselective $\mathrm{Cu}$-catalyzed AAA to prochiral materials can now be readily achieved by an array of nucleophiles, ligands, and leaving groups. ${ }^{1,2,10,12-18}$ While numerous mechanistic overviews have been outlined, detailed analyses of asymmetric $\mathrm{Cu}$ catalyzed pathways are scarce and rely on analogy with work on stoichiometric nonenantioselective methods. To date, the most insight into these mechanisms has been brought by the Bäckvall, ${ }^{19-21}$ Nakamura, ${ }^{6,22-24}$ Alexakis, ${ }^{25}$ and Feringa ${ }^{10}$ groups, all of which clearly emphasize the complexity of these mechanisms and the challenges associated with their study.

Most nonstabilized nucleophiles $\left(\mathrm{R}_{2} \mathrm{Zn}, \mathrm{RMgX}\right.$, and $\left.\mathrm{AlR}_{3}\right)$ used in asymmetric $\mathrm{Cu}$-catalyzed reactions are assumed to undergo transmetalation to $\mathrm{Cu}$-species as a key step. However, to our knowledge, spectroscopic demonstration of trans- metalation has only been observed in the addition of Grignard reagents to precatalytic $\mathrm{Cu}$-ferrocenyl dimers, ${ }^{26}$ addition of diorganozinc nucleophiles to $\mathrm{Cu}$-phosphoramidite ligand complexes, $^{27}$ and for organolithium reagents used in $\mathrm{Cu}$ catalyzed AAAs. ${ }^{28}$ Upon addition of the allylic substrate, oxidative addition is believed to occur, providing many plausible $\sigma$ - or $\pi$-Cu-substrate complexes, which may rapidly interconvert and involve various $\mathrm{S}_{\mathrm{N}} 2$ or $\mathrm{S}_{\mathrm{N}} 2^{\prime}$ and syn or anti mechanisms and is followed by reductive elimination (Figure 1a). What controls the overall chemo-, regio-, and enantioselectivity of these reactions is a subtle combination of variables and is not well understood.

$\mathrm{Cu}$-AAAs using chiral racemic substrates are rare. ${ }^{25,29-35}$ Racemic electrophiles bring even more mechanistic complexity, as the relative rates of addition, isomerization, and elimination of two different chiral starting material/catalyst combinations must be considered. The vast majority of asymmetric reactions involving racemic substrates and a chiral catalyst are kinetic resolutions. $^{36-41}$ To overcome the limitation of incomplete conversions ( $50 \%$ maximum theoretical yield), elegant processes have been designed to transform both enantiomers

Received: March 10, 2017

Published: March 31, 2017 


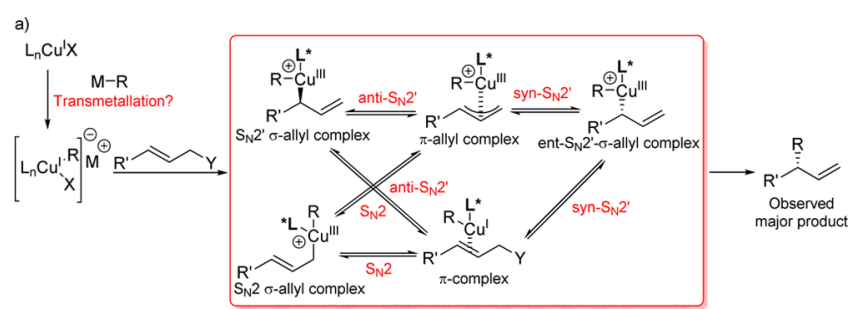

b)

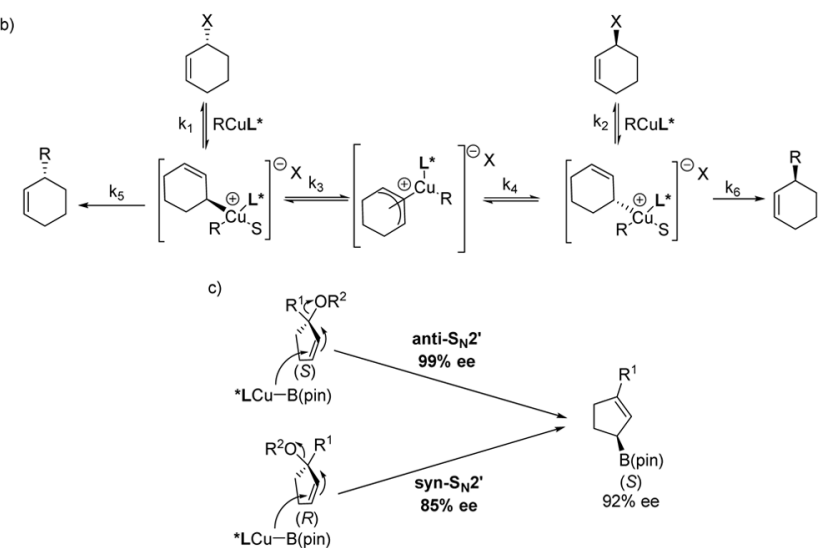

Figure 1. Mechanisms of copper-catalyzed asymmetric allylic alkylations. (a) Generally understood mechanism using prochiral starting materials; this process is highly complex and still not well understood. (b) Initially proposed mechanism for a $\mathrm{Cu}$-catalyzed AAA with racemic allyl bromides and Grignard reagents. ${ }^{25,32,33}$ (c) Example of a Cu-catalyzed direct enantioconvergent transformation. ${ }^{34}$

of racemic starting materials into a single enantiomer of product. Dynamic kinetic resolution ${ }^{38,42,43}$ (DKR) involves the rapid racemization of the starting material while only one enantiomer of the starting material reacts. As far as we are aware no $\mathrm{Cu}$-catalyzed methods have been developed which apply the DKR strategy. Dynamic kinetic asymmetric transformations ${ }^{9,32,44-48}$ (DYKATs) are deracemization/symmetrization methods where both enantiomers of starting material are converted into a common intermediate, usually a pseudoprochiral $\pi$-complex as seen in Pd- or Ir-chemistry.

Alexakis reported $\mathrm{Cu}$-AAAs of Grignard reagents with racemic cyclic allylic bromides which were initially suspected to proceed through DYKAT mechanisms ${ }^{25,32,33}$ (Figure 1b) where racemic allyl bromides would form diastereomeric $\sigma-\mathrm{Cu}$ complexes that rapidly desymmetrize via $\pi$-allyl complexes. However, a detailed study by Alexakis and co-workers using a combination of experimental and computational analyses upended the initially proposed mechanism. ${ }^{25}$ A series of insightful studies concluded that in these reactions the catalyst promotes a distinct reaction pathway for each enantiomer to provide a common product. Such reactions are direct enantioconvergent transformations (DETs). ${ }^{25,34}$

There are other examples of DETs providing very high yields and enantioselectivity, even though the design of DETs is presumably extremely challenging, as substrate- and catalystcontrolled selectivities need to be somehow balanced. For example, Sawamura ${ }^{34}$ described a Cu-catalyzed DET of boronic ester nucleophiles to racemic cyclic esters (Figure 1c). This group has recently reported a different $\mathrm{Cu}$-catalyzed AAA with linear racemic species that may involve multiple allylcopper(III) species in rapid equilibrium. ${ }^{35}$

In some cases considerable mechanistic insight into complex organometallic reactions can be elucidated by in situ NMR spectroscopic studies. ${ }^{6,49-53}$ Mechanistic NMR studies of asymmetric $\mathrm{Cu}$-catalyzed methods are rare, presumably because of the high reactivity of the reagents (requiring cryogenic temperatures and rigorously dry conditions), the complexity of the reactions, the sensitivity of these processes to reaction parameters (requiring expensive NMR solvents), and the large quadrupole moment of $\mathrm{Cu}$ precluding its ready observation by NMR. Primary organocopper(I) species are dynamic and reactive entities with a tendency to aggregate, resulting in complex mixtures of species. ${ }^{50}$ Here aggregation and reactivity are strongly linked to reaction outcome (yield, chemo- and enantioselectivity) and are highly dependent on solvent interactions, counterion and ligand effects, and more tractable variables such as concentration and temperature. $3,26,50,54-56$ Gschwind's elegant work shed light on the nature of precatalytic $\mathrm{Cu}$-complexes in solution using NMR spectroscopy. $^{27,57-60}$

We recently reported a $\mathrm{Cu}$-catalyzed AAA with racemic cyclic allyl chlorides $\mathbf{1}$ and alkylzirconocenes using $\mathrm{CuI}-\mathbf{A}$ (Scheme 1). ${ }^{61}$ A variety of highly enantioenriched products could be

Scheme 1. Cu-AAA Using Racemic Cyclic Allyl Chloride 1 and Alkylzirconocenes ${ }^{61}$

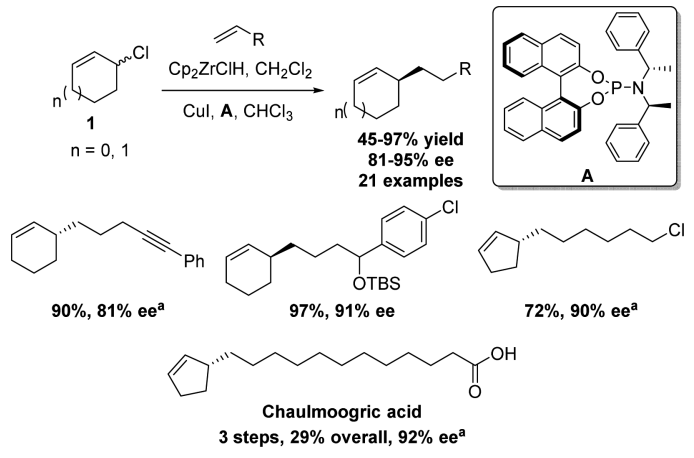

${ }^{a}$ Prepared using $(R, R, R)-\mathbf{A}$.

obtained at room temperature in high yield, and the method was also used to synthesize bioactive natural products used as traditional treatments for tuberculosis and leprosy.

During this work we observed a clear dependence between ee and $\mathrm{Cu}$-halides (Figure 2a, entries $1-3$ ). CuI gave the best results which we attribute to the iodide promoting racemization of the starting material. However, CuOTf also provided products with reasonably high levels of ee ( $71 \%$ ee, entry 5$)$.

${ }^{1} \mathrm{H}$ NMR spectroscopic studies aimed at identifying the pathways involved were carried out by in situ NMR and showed clean and slow conversion of allyl chloride $\mathbf{1}$ to product, as well as the constant presence of allyl iodide 2 in low ( $3 \mathrm{~mol} \%)$ concentrations. The CuI-A catalyst is believed to form $\mathbf{2}$ from 1 via $S_{N} 2^{\prime}$ chemical exchanges, as observed by EXSY (Figure $2 b$ ) and we speculated that this reaction would racemize 2 . Further studies using allyl bromide showed that $\mathrm{CuI}-\mathbf{A}$ both formed allyl iodide $\mathbf{2}$ and mediated isomerization of the allyl bromide. Further, interconversion between allyl bromide and $\mathbf{2}$ occurs solely by $S_{N} 2^{\prime}$ mechanisms on the NMR time scale. We also observed deshielding of catalyst benzylic signals over the course of the reaction by ${ }^{1} \mathrm{H}$ NMR spectroscopy (Figure 2c). ${ }^{62}$ Interestingly, this correlates well to an increase in the ee of the product over time: from $85 \%$ ee at $10 \mathrm{~min}, 90 \%$ ee at $2 \mathrm{~h}$, and $95 \%$ ee overnight. It would seem that the catalytic species are evolving toward a more highly enantioselective catalyst, and we 

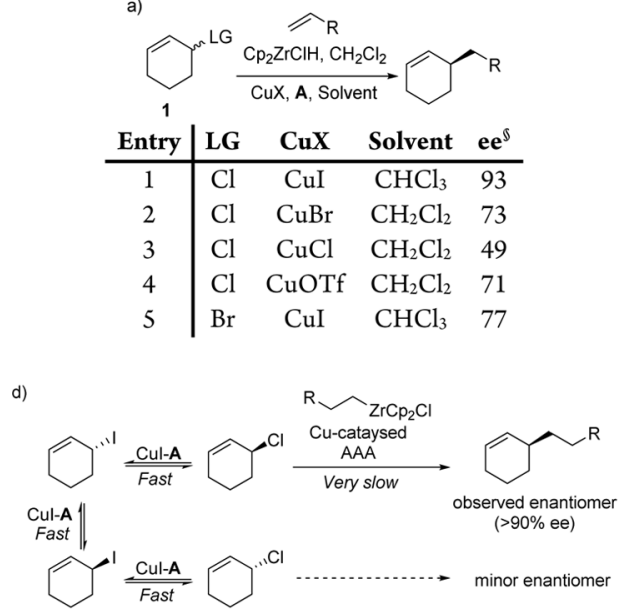
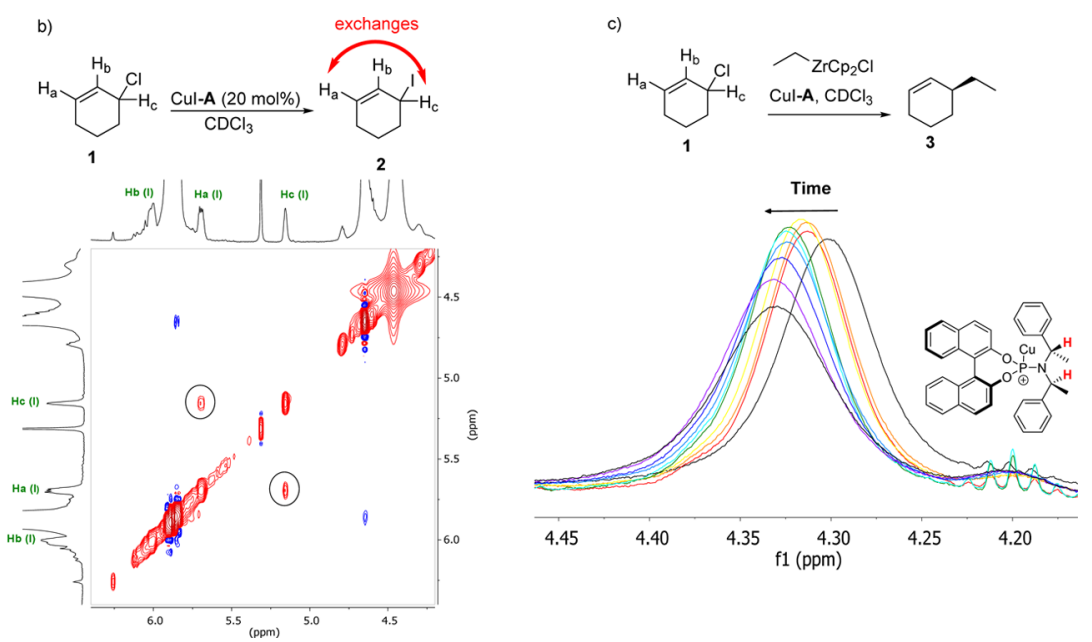

Figure 2. Previously described experiments and initial mechanistic observations. (a) Selected screening experiments. (b) 2D NMR EXSY (800 ms mixing time) during Cu-AAA reaction. (c) The chemical shift of a ligand benzylic ${ }^{1} \mathrm{H}$ signal over the course of the reaction. Spectra taken at different times following the visible light spectrum of color for clarity. (d) Proposed mechanism of Cu-catalyzed AAA of allyl chloride 1 using alkylzirconocenes.
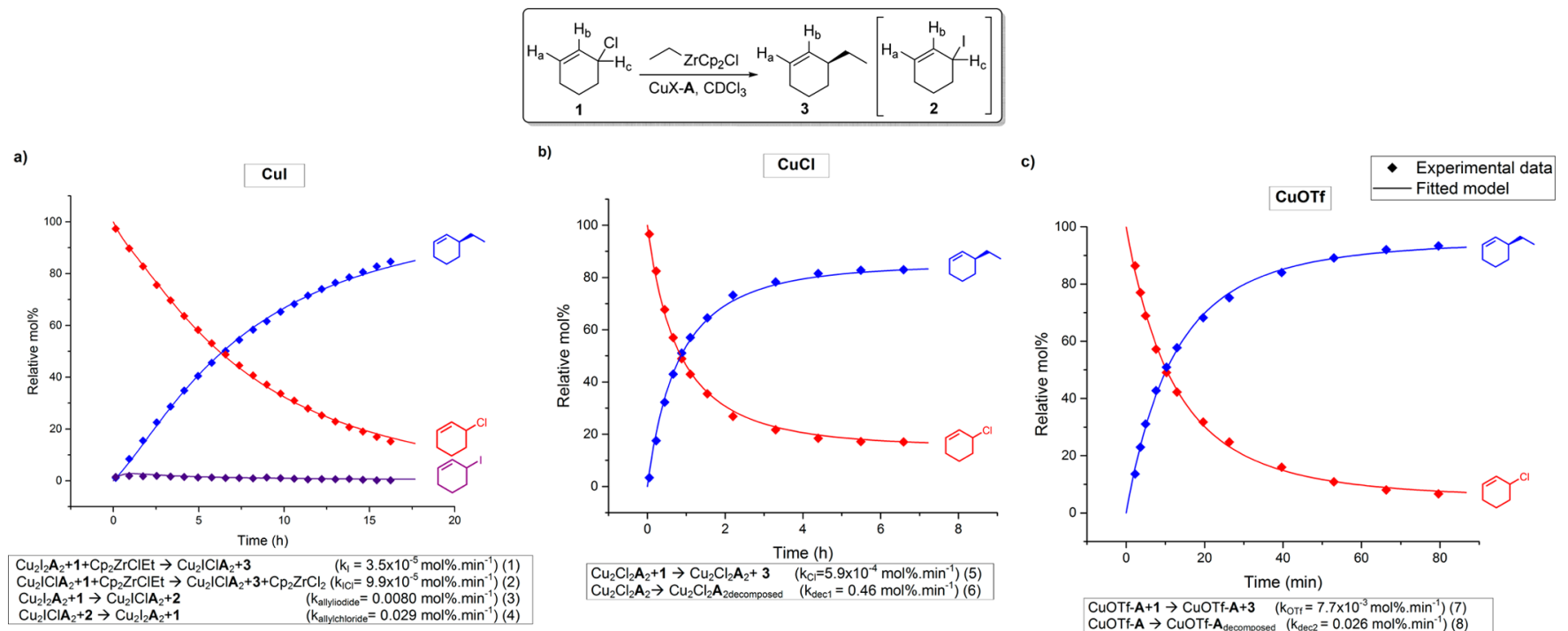

Figure 3. Experimental and modeled kinetic data of $\mathrm{Cu}$-AAA with $\mathbf{1}$ as monitored by in situ ${ }^{1} \mathrm{H}$ NMR spectroscopy using (a) $\mathrm{CuI},(\mathrm{b}) \mathrm{CuCl}$, and (c) CuOTf. Conditions: ethylene ( $1 \mathrm{~atm}), \mathrm{Cp}_{2} \mathrm{ZrClH}$ (2.0 equiv), $\mathrm{CD}_{2} \mathrm{Cl}_{2}, \mathrm{CuX}(10 \mathrm{~mol} \%),(S, S, S)-\mathbf{A}(10 \mathrm{~mol} \%)$, allyl chloride $\mathbf{1}$ (1.0 equiv), in $\mathrm{CDCl}_{3}, 298 \mathrm{~K}$. The experimental data recorded by ${ }^{1} \mathrm{H}$ NMR are shown as diamonds. Based on those data points, modeling was performed using Dynafit4. The fitted curves are shown as solid lines, and the input equations with their rates are below the corresponding graphs.

speculated that the catalyst species evolved to contain chloride anions during the reaction.

Based on these experiments we proposed the mechanism shown in Figure 2d. This does not provide any insight into the $\mathrm{C}-\mathrm{C}$ bond-forming step, but is suggestive of a generally useful pathway for racemic starting materials where a catalyst selects one enantiomer of an allylic substrate for the reaction, while racemization of the starting material replenishes the more reactive enantiomer. Overall such a process may be highly stereoselective, depending on the kinetics (as well as selectivity and robustness) of all of these different processes. $\mathrm{A} \mathrm{Cu}$ catalyzed heterocyclic AAA of alkylzirconocenes to racemic 3,6dihydro- $2 \mathrm{H}$-pyrans was also developed. ${ }^{63}$ Unfortunately these systems do not work well, but showed remarkable mechanistic diversity for a priori similar conditions.

Several aspects of these AAA mechanisms remain to be elucidated, in particular, details of the Cu-catalyzed AAA step, the structure and dynamics of the catalyst, and also the rate, robustness, and generality of the racemization process. Here we describe detailed studies using a combination of structureactivity relationships, new reaction development, isotopic labeling, NMR spectroscopy, and kinetic modeling.

\section{RESULTS AND DISCUSSION}

Kinetics via in Situ ${ }^{1} \mathrm{H}$ NMR Spectroscopy. Based on our previous insights using ${ }^{1} \mathrm{H}$ NMR spectroscopy, we decided to obtain kinetic data in situ. We were able to follow the reaction in time, showing consumption of starting material $\mathbf{1}$, formation of product $\mathbf{3}$, and the presence of allyl iodide intermediate $\mathbf{2}$ on a CuI-catalyzed reaction as shown in Figure 3a. Using nonlinear least-squares regression on DynaFit $4,{ }^{64}$ we attempted to build a simple model of the reaction while taking into account the reversible formation of $\mathbf{2}$. Attempts to fit the data always led to significant divergence of the model from experiment (see 
Supporting Information (SI) p S46). In order to obtain a reasonable fit we had to take into account the modification of the catalyst observed by NMR (Figure $2 c$ ) $^{61}$ and speculate that the leaving group generates chloride anions during AAA (Figure 3a, eq 1) which become incorporated into the catalyst and generates a more enantioselective catalyst as the reaction proceeds; perhaps the simplest form of the second generation catalyst would be $\mathrm{Cu}_{2} \mathrm{IClA}_{2}$, a dimer of CuIA where one halogen has been replaced by $\mathrm{Cl}$. A model using $\mathrm{Cu}_{2} \mathrm{IClA}_{2}$ as a second "reaction-enhanced" catalyst (eq 2) suggested that this AAA is 3 times faster than AAA with the starting catalyst (eq 1). Chemical exchange between $\mathbf{2}$ and $\mathbf{1}$ is relatively fast: $k_{\text {allyl iodide }}$ $=0.0080 \mathrm{~mol} \% \cdot \mathrm{min}^{-1}$ for formation of 2 (eq 3) with regeneration of 1 being more than 3 times faster $\left(k_{\text {allyl chloride }}=\right.$ $0.029 \mathrm{~mol} \% \cdot \mathrm{min}^{-1}$, eq 4$)$. This model supports the idea that AAA is slow compared to isomerization of 1 and $2\left(>10^{2}\right.$ times slower), allowing replenishment of the reactive enantiomer of 1.

In situ ${ }^{1} \mathrm{H}$ NMR spectroscopic kinetic studies were also carried out for the $\mathrm{CuCl}$ and CuOTf catalyzed AAA (Figure $3 \mathrm{~b}$ and $3 \mathrm{c}$ respectively). The obtained experimental data were fitted by nonlinear least-squares regression. ${ }^{64}$ In the case of $\mathrm{CuCl}$ (Figure 3b) we observe clean conversion of 1 to 3 , but the reaction ceases in the NMR tube after $5 \mathrm{~h}$ and has a half-life of $1 \mathrm{~h}$. In reaction flasks, the ee of the product obtained using the $\mathrm{CuCl}$ catalyst decreases over time: $82 \%$ ee at $10 \mathrm{~min}, 68 \%$ ee at $2 \mathrm{~h}$, and $54 \%$ ee at completion. EXSY experiments suggest that $\mathrm{CuCl}-\mathrm{A}$ does not isomerize $\mathbf{1}$ on the NMR relaxation time scale (see SI p S73). This is consistent with studies on recovered 1 during the $\mathrm{CuCl}$ catalyzed reactions, which show the formation on nonracemic 1 ( $\sim 7 \%$ ee after $1 \mathrm{~h},>11 \%$ ee after $2 \mathrm{~h}$ ) as judged by GC analysis (see SI p S51).

With CuOTf, AAA is much faster than with $\mathrm{Cu}$ halides and stops within $\sim 80 \mathrm{~min}$ as determined by in situ ${ }^{1} \mathrm{H}$ NMR spectroscopy (Figure 3c). Another feature of the $\mathrm{OTf}^{-}$reaction is that the ee of the product stays constant over time ( $71 \%$ ee). In the modeling, a good fit was obtained by taking into account that the reaction does not go to completion because of catalyst decomposition. Decomposition was calculated to occur at $k_{\mathrm{dec} 2}$ $=0.026 \mathrm{~mol} \% \cdot \mathrm{min}^{-1}, \sim 3 \times$ faster than the CuOTf-A catalyzed $\mathrm{C}-\mathrm{C}$ bond formation $\left(k_{\mathrm{OTf}}=7.7 \times 10^{-3} \mathrm{~mol} \% \cdot \mathrm{min}^{-1}\right)$. This catalyst instability is consistent with our qualitative observations on the reactivity of CuOTf complexes.

As the CuI AAA is $\sim 10$ times slower than with $\mathrm{CuCl}\left(k_{\mathrm{Cl}}=\right.$ $\left.5.9 \times 10^{-4} \mathrm{~mol} \% \cdot \mathrm{min}^{-1}\right)$ and $10^{2}$ times slower than with CuOTf $\left(k_{\text {OTf }}=7.7 \times 10^{-3} \mathrm{~mol} \% \cdot \mathrm{min}^{-1}\right)$, the $\mathrm{Cu}$ counterion impacts the catalytic species present throughout the reaction.

Upon addition of $\mathrm{Cp}_{2} \mathrm{ZrClEt}$ to $\mathrm{CuI}-\mathrm{A}$, we do not observe any color changes or significant changes in ${ }^{1} \mathrm{H}$ and ${ }^{31} \mathrm{P}$ NMR spectra. We speculate that $\mathrm{CuI}-\mathrm{A}$ and $\mathrm{Cp}_{2} \mathrm{ZrClEt}$ do not react before addition of 1 even though most mechanistic proposals with nonstabilized nucleophiles involve transmetalation processes. $^{1,2,26,27,65}$ In contrast, upon addition of $\mathrm{Cp}_{2} \mathrm{ZrClEt}$ to $\mathrm{CuCl}-\mathrm{A}$, a yellow to dark brown color change occurs within a few minutes and changes are observed by ${ }^{1} \mathrm{H}$ and ${ }^{31} \mathrm{P}$ NMR spectroscopy (see SI p S50). In the ${ }^{31} \mathrm{P}$ NMR spectra, the peak associated with $\mathrm{CuCl}-\mathbf{A}$ drastically broadens without a significant change of chemical shift. At completion, the strong ${ }^{31} \mathrm{P}$ NMR signals earlier seen at $140-120 \mathrm{ppm}$ disappear, suggesting catalyst decomposition, consistent with our kinetics and modeling (see Figure $3 \mathrm{~b}$ ). It appears that precatalytic CuOTf-A exists as at least two entities in a 1:0.3 ratio in $\mathrm{CDCl}_{3}$ at $298 \mathrm{~K}$ as there are two sets of distinct benzylic and methyl signals in the ${ }^{1} \mathrm{H}$ NMR and two signals in the ${ }^{31} \mathrm{P}$ NMR spectrum (see SI p S23). With CuOTf-A, upon addition of $\mathrm{Cp}_{2} \mathrm{ZrClEt}$ the reaction mixture turns brown instantaneously and changes are observed in the ${ }^{1} \mathrm{H}$ and ${ }^{31} \mathrm{P}$ NMR spectra suggesting the formation of a single species. From the information gathered, the mechanism of CuOTf-A catalyzed AAA appears to be different than that of $\mathrm{Cu}$-halide-A complexes.

Supramolecular Structures of the Precatalytic Complexes. In an attempt to gain insight into the structure of the active catalysts we carried out diffusion NMR spectroscopy experiments. Gschwind extensively used these to study precatalytic Cu-phosphoramidite complexes at $220 \mathrm{~K}^{58,59,66}$ and found that the diffusion coefficients obtained are accurate enough to determine the number of ligands in a complex, but not the number of salt units. ${ }^{57,58}$ Morris et al. ${ }^{67}$ have described a pragmatic correlation function, using the concept of an effective mean density for solute and solvent molecules, to estimate the molecular weight of a small-molecule species based on its diffusion coefficient. We note that although the correlation was developed and demonstrated only for molecules comprising light atoms $(<\mathrm{Cl})$, the estimated molecular weights would nevertheless help us establish the presence of supramolecular assemblies of $\mathbf{C u X}-\mathbf{A}$ complexes since the ligand unit makes up the bulk of the molecular weight $\left(540 \mathrm{~g} \cdot \mathrm{mol}^{-1}\right)$ as opposed to the heavy atom $\mathrm{Cu}\left(64 \mathrm{~g} \cdot \mathrm{mol}^{-1}\right)$ and halides $(35$ $\mathrm{g} \cdot \mathrm{mol}^{-1}$ for $\mathrm{Cl}, 127 \mathrm{~g} \cdot \mathrm{mol}^{-1}$ for I).

Alternatively, calibration curves have also been used to determine the molecular weight of supramolecular complexes. ${ }^{68-70}$ We thus ran diffusion experiments on known $\mathrm{Rh}$ and $\mathrm{Pd}$ complexes in $\mathrm{CDCl}_{3}$ to generate a calibration curve (see SI p S54). These experiments show, similar to Gschwind's results, that $\mathrm{D}$ has limited ability to predict the stoichiometry of small bridging salts such as halides, but as stated above, these methods may still be used to estimate the molecular weight of the supramolecular complexes here, as ligands make up the bulk of the molecular weight.

We therefore carried out diffusion experiments with convection compensation ${ }^{71,72}$ of different $\mathrm{CuX}-\mathbf{A}$ complexes at $298 \mathrm{~K}$ in $\mathrm{CDCl}_{3}$. These experiments were measured in triplicate at $0.05 \mathrm{M}$, the same concentration as the catalytic species in the reaction. First as a control, we measured the diffusion coefficient of free ligand $\mathbf{A}$ to be $(8.74 \pm 0.16) \times$ $10^{-10} \mathrm{~m}^{2} \cdot \mathrm{s}^{-1}$ (Table $1-$ entry 1 ). The diffusion coefficient of A correlates to an estimated molecular weight of $542 \pm 21 \mathrm{~g}$. $\mathrm{mol}^{-1}$ using Morris' correlation, close to the actual value of 540 $\mathrm{g} \cdot \mathrm{mol}^{-1}$.

The diffusion coefficient of $\mathrm{CuI}-\mathrm{A}$ in $\mathrm{CDCl}_{3}$ at $298 \mathrm{~K}$ was measured to be $(6.13 \pm 0.05) \times 10^{-10} \mathrm{~m}^{2} \cdot \mathrm{s}^{-1}$ (entry 2) which correlates to an estimated molecular weight of $1163 \pm 20 \mathrm{~g}$. $\mathrm{mol}^{-1}$. As the measured diffusion coefficient is consistent with a complex containing two ligands A $\left(>1080 \mathrm{~g} \cdot \mathrm{mol}^{-1}\right)$, we propose the species is a dimer of the formula $\mathrm{Cu}_{2} \mathrm{I}_{2} \mathrm{~A}_{2}(1460$ $\mathrm{g} \cdot \mathrm{mol}^{-1}$ ) rather than a monomer (CuIA, $730 \mathrm{~g} \cdot \mathrm{mol}^{-1}$ ). We however note that we cannot rule out other species, as there are uncertainties in these measurements.

$\mathrm{CuCl}-\mathbf{A}$ in $\mathrm{CDCl}_{3}$ had a diffusion coefficient of $(5.87 \pm$ $0.09) \times 10^{-10} \mathrm{~m}^{2} \cdot \mathrm{s}^{-1}$ (entry 3 ), which suggests a molecular weight of $1279 \pm 46 \mathrm{~g} \cdot \mathrm{mol}^{-1}$. Unlike the above result with I atoms, this prediction actually correlates very well with a $\mathrm{Cu}_{2} \mathrm{Cl}_{2} \mathrm{~A}_{2}$ dimer $\left(\mathrm{MW}=1277 \mathrm{~g} \cdot \mathrm{mol}^{-1}\right)$. We also measured the diffusion coefficient of mixed $\mathrm{CuI}-\mathbf{A} / \mathrm{CuCl}-\mathbf{A}$ complexes in a 1:1 ratio (entry 4) in an attempt to mimic the possible structure 
Table 1. Diffusion Coefficients D, and Estimated Molecular Weight, As Measured by NMR Spectroscopy ${ }^{a, b}$

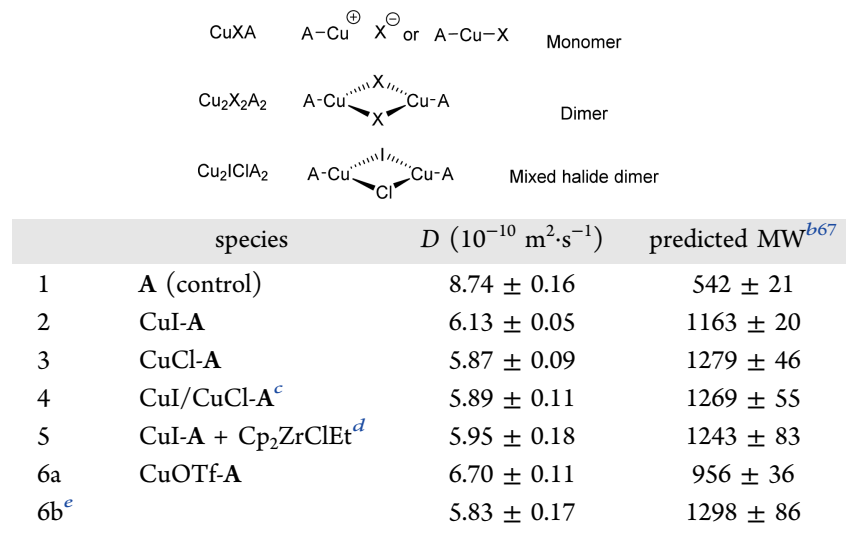

${ }^{a}$ Conditions: $\mathrm{CuX}(10 \mathrm{~mol} \%),(S, S, S)-\mathbf{A}(10 \mathrm{~mol} \%)$ in $\mathrm{CDCl}_{3}$ at 298 $\mathrm{K} .{ }^{b}$ Note that this technique is not accurate enough to determine halide numbers., ${ }^{57,58}$ see accompanying text. ${ }^{c} \mathrm{CuI}(5 \mathrm{~mol} \%), \mathrm{CuCl}(5$ $\mathrm{mol} \%),(S, S, S)-\mathbf{A}(10 \mathrm{~mol} \%)$ in $\mathrm{CDCl}_{3}, 298 \mathrm{~K} .{ }^{d}$ Ethylene (1 atm), $\mathrm{Cp}_{2} \mathrm{ZrClH}$ (2.0 equiv) in $\mathrm{CD}_{2} \mathrm{Cl}_{2}, \mathrm{CuX}(10 \mathrm{~mol} \%),(S, S, S)-\mathbf{A}(10 \mathrm{~mol}$ $\%)$ in $\mathrm{CDCl}_{3}$ at $298 \mathrm{~K}$. ${ }^{e}$ Calculated for a broader component at 7.072$6.761 \mathrm{ppm}$. The error values were calculated from the standard deviation of diffusion coefficient found for the $\mathrm{CH}-\mathrm{N}$ signals at 4.65$4.31 \mathrm{ppm}$ and the aromatic signals of the catalyst in each diffusion experiment, which were run in triplicate.

of the enhanced enantioselective catalyst generated during AAA. The diffusion coefficient was $(5.89 \pm 0.11) \times 10^{-10} \mathrm{~m}^{2}$. $\mathrm{s}^{-1}$, a value very close to that observed with the $\mathrm{CuCl}-\mathrm{A}$ complex.

When adding $\mathrm{Cp}_{2} \mathrm{ZrClEt}$ to $\mathrm{CuI}-\mathbf{A}$, the diffusion coefficient was $(5.95 \pm 0.18) \times 10^{-10} \mathrm{~m}^{2} \cdot \mathrm{s}^{-1}$ (entry 5), within experimental error of the diffusion coefficient for both CuI$\mathbf{A}$ and $\mathrm{CuCl}-\mathbf{A}$, which, taken together with the lack of change observed in the ${ }^{1} \mathrm{H}$ and ${ }^{31} \mathrm{P}$ NMR spectra when $\mathrm{Cp}_{2} \mathrm{ZrClEt}$ and $\mathrm{CuI}-\mathbf{A}$ are mixed, suggests that the dimeric aggregates do not change significantly in the presence of the nucleophile.

The diffusion coefficient of CuOTf-A, which the ${ }^{1} \mathrm{H}$ and ${ }^{31} \mathrm{P}$ NMR spectra suggest is two complexes in solution at $298 \mathrm{~K}$, was $(6.70 \pm 0.11) \times 10^{-10} \mathrm{~m}^{2} \cdot \mathrm{s}^{-1}$ (entry 6a), associated with a molecular weight of $956 \pm 36 \mathrm{~g} \cdot \mathrm{mol}^{-1}$. Even with the assumption that ionic triflate pseudohalides are absent from the complex, this value is too low for a dimer $\left(\mathrm{Cu}_{2} \mathrm{~A}_{2}{ }^{2+}, 1206 \mathrm{~g}\right.$. $\left.\mathrm{mol}^{-1}\right)$ but too high for a monomer $\left(\mathrm{CuA}^{+}, 603 \mathrm{~g} \cdot \mathrm{mol}^{-1}\right)$ and the observed diffusion coefficient may be an average of the two CuOTf-A complexes found in solution. Measuring the diffusion coefficient for a broader component at 7.072-6.671 ppm resulted in a diffusion coefficient of $(5.83 \pm 0.17) \times 10^{-10}$ $\mathrm{m}^{2} \cdot \mathrm{s}^{-1}$, corresponding to a molecular weight of $1298 \pm 86 \mathrm{~g}$. $\mathrm{mol}^{-1}$ (entry 6b) and possibly dimeric $\mathrm{Cu}_{2} \mathbf{A}_{2} \mathrm{OTf}_{2}$ (1504 g. $\mathrm{mol}^{-1}$ ). Due to extensive NMR signal overlap we were unable to obtain diffusion ordered (DOSY) data, in which each complex could be separated.

Examining the correlation between the ee of the ligand and the ee of the product in the $\mathrm{CuI}$ catalyzed reaction shows a negative nonlinear effect (Figure 4),,$^{73-75}$ consistent with the active catalyst being an oligomer in ligand.

Isomerization of Allyl lodide 2. We first decided to examine various conditions which may mediate the formation of $\mathbf{2}$ from $\mathbf{1}$ and its isomerization. Using $\mathrm{CuI}$ and $\mathrm{CDCl}_{3}, \mathbf{2}$ was only observed when used in combination with a phosphine ligand (A, BINAP, or $\mathrm{PPh}_{3}$, Table 2, entries 1-3). The absence

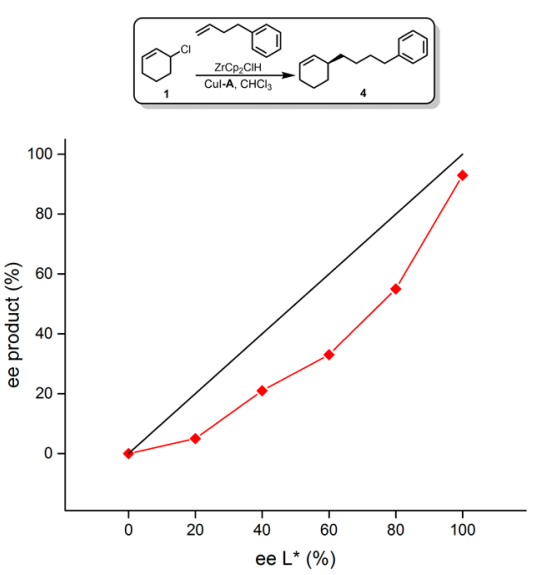

Figure 4. Negative nonlinear effect observed in the CuI-A catalyzed AAA of 1. Conditions: 4-phenyl-1-butene (2.5 equiv), $\mathrm{Cp}_{2} \mathrm{ZrHCl}$ (2.0 equiv) in $\mathrm{CH}_{2} \mathrm{Cl}_{2}, \mathrm{CuX}(10 \mathrm{~mol} \%),(S, S, S)$-A (10 mol \%), allyl chloride 1 ( 1.0 equiv), in $\mathrm{CHCl}_{3}$, room temperature.

Table 2. Testing the Generality of Allyl Iodide 2 Formation/ Isomerization $^{a}$

\begin{tabular}{cclllc} 
entry & $\mathrm{I}^{-}$source & ligand & \multicolumn{1}{c}{ solvent } & allyl iodide & exchanges \\
1 & $\mathrm{CuI}$ & $\mathbf{A}$ & $\mathrm{CDCl}_{3}$ & yes & yes \\
2 & $\mathrm{CuI}$ & $\mathrm{Binap}$ & $\mathrm{CDCl}_{3}$ & yes & yes \\
3 & $\mathrm{CuI}$ & $\mathrm{PPh}_{3}$ & $\mathrm{CDCl}_{3}$ & yes & yes \\
4 & $\mathrm{CuI}$ & $\mathrm{NHC}^{b}$ & $\mathrm{CDCl}_{3}$ & no & - \\
5 & $\mathrm{CuI}$ & $\mathrm{Me}_{2} \mathrm{~S}$ & $\mathrm{CDCl}_{3}$ & traces & no \\
6 & $\mathrm{CuI}$ & - & $\mathrm{CDCl}_{3}$ & no & - \\
7 & $\mathrm{TBAI}$ & - & $\mathrm{CDCl}_{3}$ & yes & no \\
8 & TMSI & - & $\mathrm{CDCl}_{3}$ & yes & yes \\
9 & $\mathrm{CuI}$ & $\mathbf{A}$ & benzene-d & yes & yes \\
10 & $\mathrm{CuI}$ & $\mathbf{A}$ & $\mathrm{THF}_{6} d_{8}$ & yes & yes \\
11 & $\mathrm{CuI}$ & $\mathbf{A}$ & $\mathrm{CD}_{3} \mathrm{CN}$ & yes & yes
\end{tabular}

${ }^{a}$ Conditions: Iodide source $(10 \mathrm{~mol} \%$ for CuI, $1.0 \mathrm{eq}$ for TMSI and TBAI), ligand (10 mol \%), allyl chloride 1 (1.0 equiv), in solvent, 298 K. ${ }^{b} \mathrm{NHC}$ ligand used: 1-(S)-Leucinol-3-(2,4,6-trimethylphenyl)-3Himidazolium hexafluorophosphate.

of ligand (entry 6) or use of N-heterocyclic carbene (NHC) (entry 4 ) or sulfur (entry 5) based ligands either gave no 2 or only traces of 2 . Alternative $\mathrm{I}^{-}$sources such as tetrabutylammonium iodide (TBAI) (entry 7) and iodotrimethylsilane (TMSI) (entry 8) formed 2 in $4 \%$ and $70 \%$ yield, respectively. Although 2 was formed in the presence of TBAI, no exchanges by EXSY were observed (entry 7 ), whereas in other cases when 2 was formed it was rapidly isomerizing. Using CuI-A, formation and isomerization of $\mathbf{2}$ occurred in all solvents examined $\left(\mathrm{CDCl}_{3}\right.$, benzene, THF, $\left.\mathrm{MeCN}\right)$.

$\mathrm{CuCl}-\mathrm{A}$ catalyzed reactions (which normally give $49 \%$ ee, Figure 2a, entry 3) carried out in the presence of $10 \mathrm{~mol} \%$ TMSI gave 4 in $76 \%$ ee, while a reaction with $10 \mathrm{~mol} \%$ TBAI gave $\mathbf{4}$ in $52 \%$ ee, supporting the idea that allyl halide isomerization (Table 2, entries 7 vs 8 ) is crucial to obtaining high enantioselectivity in these reactions.

Under the reaction conditions used for the highly enantioselective AAA we set out to quantify the exchange observed in 2 using NMR spectroscopy (Table 3). We first used selective $1 \mathrm{D}-\mathrm{EXSY}^{76,77}$ at various temperatures and 
Table 3. Allyl Iodide Isomerization Rate Measurements by Multiple NMR Experiments ${ }^{a}$

\begin{tabular}{|c|c|c|c|}
\hline entry & experiment & $T(\mathrm{~K})$ & rate of isomerization $\left(\mathrm{s}^{-1}\right)$ \\
\hline 1 & 1D-EXSY & 273 & 0.02 \\
\hline 2 & 1D-EXSY & 298 & 0.11 \\
\hline 3 & 1D-EXSY & 313 & 0.60 \\
\hline 4 & inversion recovery & 298 & 0.10 \\
\hline 5 & SSTD & 298 & 0.08 \\
\hline
\end{tabular}

${ }^{a}$ Conditions: $\mathrm{CuI}(10 \mathrm{~mol} \%),(S, S, S)-\mathbf{A}(10 \mathrm{~mol} \%)$, allyl chloride $\mathbf{1}$ (1.0 equiv), in $\mathrm{CDCl}_{3}$, room temperature. NMR spectra recorded at indicated temperature.

derived the $\mathrm{Ha} / \mathrm{Hc}$ exchange rate constants from the initial slopes of normalized intensity build-up profiles (entries 1-3; see SI p S75). These results show the rate of $\mathrm{Ha} / \mathrm{Hc}$ exchange in 2 exponentially increases with respect to temperature. To corroborate these data, we also ran selective inversion transfer ${ }^{53,78-80}$ (entry 4) and spin saturation transfer difference $(\text { SSTD })^{81}$ experiments (entry 5) at $298 \mathrm{~K}$ (see SI p S75). All three methods gave similar results emphasizing the validity and accuracy of the results. The data analyses also yielded longitudinal relaxation time constants $\left(\mathrm{T}_{1}\right.$ 's $)$ for the protons of 2 which were observed to be unusually large, with values ranging from 15 to $25 \mathrm{~s}$ for $\mathrm{Ha}, \mathrm{Hb}$, and $\mathrm{Hc}$ (see SI p S75). These values were comparable to those determined from (nonselective) inversion recovery experiments for $\mathbf{1}$ and $\mathbf{2}$, and we attribute these large values to use of the argon degassing and lack of paramagnetic $\mathrm{O}_{2}$ in the sample.

Development of a New AAA System. It would also be desirable to use less reactive electrophiles than allyl chlorides. These may be more chemically stable and less prone to isomerization during formation or routine manipulations. Furthermore, we anticipated that less reactive starting materials would aid mechanistic studies described in the next section. From this perspective, we attempted to develop a new AAA with alternative allyl species. Different cyclic allylic alcohol derivatives were tested using our previous conditions.

Allyl acetate did not react under these conditions (Figure 5a, entry 1 ), both the trifluoroacetate and pivalate derivatives behaved poorly (entries 2 and 3), but a phosphate gave promising results (>95\% conversion, $40 \%$ ee, entry 4 ).

With allyl phosphate 5 , different copper sources (Figure $5 \mathrm{~b}$, entries 1-3) and ligands (entries 4-8) were tested. A phosphoramidite D bearing a chiral amine (see SI p S26 for preparation) gave the highest ee ( $81 \%$ ee, entry 6$)$. We examined the effect of solvents and found that nonchlorinated solvents were poorly selective. We thus tried different chlorinated solvents such as $\mathrm{CHCl}_{3}$ which gave high (85\%) ee (entry 9), $\mathrm{CCl}_{4}$ which inhibited the reaction (entry 10), and dichloroethane which gave $57 \%$ ee (entry 11 ). Although we were able to obtain $85 \%$ ee, the procedure was not very reproducible. We suspected that an impurity was causing variations in our results from run to run and tested several additives (for example entries 12-16). The AAA was surprisingly tolerant to many additives and improved to $89 \%$ ee when using diethylchlorophosphate (entry 12). After substantial experimentation, 1.0 equiv of TMSCl reproducibly gave $80 \%$ yield and $89 \%$ ee (entry 15 ), although additional
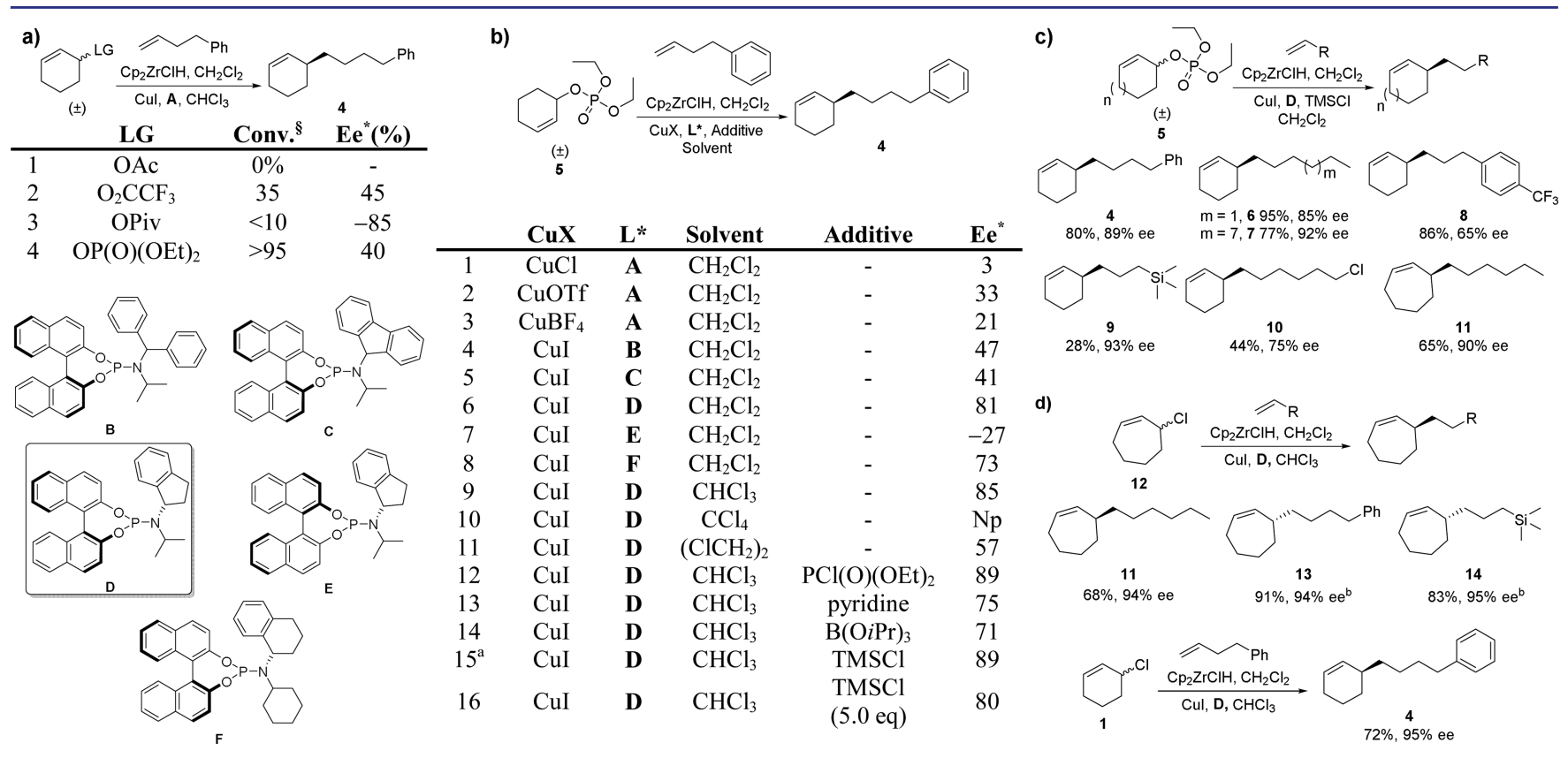

Figure 5. Development of a new AAA system. (a) Leaving group screening. Conditions: substrate (1.0 equiv), 4-phenyl-1-butene (2.5 equiv), $\mathrm{Cp}_{2} \mathrm{ZrHCl}$ (2.0 equiv), $\mathrm{CH}_{2} \mathrm{Cl}_{2}, \mathrm{CuI}(10 \mathrm{~mol} \%), \mathbf{A}(10 \mathrm{~mol} \%), \mathrm{CHCl}_{3}$, room temperature, overnight. ${ }^{\S}$ Conversion was determined by crude $\mathrm{NMR}$ *Ee was determined by HPLC. (b) Optimizing conditions. Conditions: allyl phosphate (1.0 equiv), 4-phenyl-1-butene (2.5 equiv), $\mathrm{Cp}_{2} \mathrm{ZrHCl}$ (2.0 equiv), $\mathrm{CH}_{2} \mathrm{Cl}_{2}, \mathrm{CuX}(10 \mathrm{~mol} \%), \mathrm{L}^{*}(10 \mathrm{~mol} \%)$, solvent, additive (1.0 eq unless specified), room temperature, overnight. *Ee was determined by HPLC. (c) Scope of AAA of allyl phosphate. Conditions: alkene (2.5 equiv), $\mathrm{Cp}_{2} \mathrm{ZrClH}$ (2.0 equiv), $\mathrm{CH}_{2} \mathrm{Cl}_{2}, \mathrm{CuI}(10 \mathrm{~mol} \%), \mathbf{D}(10 \mathrm{~mol} \%)$, allyl phosphate (1.0 equiv), TMSCl (1.0 equiv) in $\mathrm{CHCl}_{3}$, room temperature. (d) AAA using ligand $\mathrm{D}$ with 6-and 7-membered ring allyl chlorides. Conditions: alkene (2.5 equiv), $\mathrm{Cp}_{2} \mathrm{ZrClH}$ (2.0 equiv), $\mathrm{CH}_{2} \mathrm{Cl}_{2}, \mathrm{CuI}(10 \mathrm{~mol} \%), \mathbf{D}$ (10 mol \%), allyl chloride (1.0 equiv), in $\mathrm{CHCl}_{3}$, room temperature. ${ }^{a}$ Using $\mathrm{CH}_{2} \mathrm{Cl}_{2}$ gave the same results and was used in subsequent scope for convenience. ${ }^{b}$ Prepared using $(R, R)$-D. 
TMSCl decreased the ee (for example, 5.0 equiv, $80 \%$ ee, entry 16). When using 1.0 equiv of $\mathrm{TMSCl}$, using $\mathrm{CHCl}_{3}$ and $\mathrm{CH}_{2} \mathrm{Cl}_{2}$ gave the same results.

We then tested the scope of alkenes (Figure 5c). Products bearing simple alkyl chains (compounds 6 and 7) were obtained in high yields $(>77 \%)$ and ee's $(>85 \%$ ee). The presence of more elaborate functional groups such as $4-\mathrm{CF}_{3}-$ $\mathrm{Ph}(\mathbf{8}, 86 \%, 65 \%$ ee), TMS (9, 28\%, 93\% ee), and $\mathrm{Cl}(\mathbf{1 0}, 44 \%$, $75 \%$ ee) were tolerated but caused a decrease in the ee or the yield. We note that this AAA of allyl phosphates is more sensitive to the presence of functionalized alkene starting materials than the corresponding reactions with allyl chlorides.

When using a seven-membered allyl phosphate, we obtained 11 in good yield (65\%) with excellent $90 \%$ ee. The ability to use seven-membered rings here is important because these were not suitable substrates for the previous AAA with allyl chlorides (use of $\mathbf{1 2}$ gave $23 \%$ ee). We tested ligand D in an AAA using the seven-membered chloride 12, and excellent (94-95\% ee) enantioselectivity and good yield (>68\%) were observed for the three alkenes tested (Figure $5 \mathrm{~d}$ ).

Generally, ligand D appears to be an excellent alternative to $\mathbf{A}$ in these AAA reactions, as it allows reactions with sevenmembered substrates. Also, in the case of six-membered allyl chloride 1 we obtained a $72 \%$ yield and $95 \%$ ee, a similar result obtained with A (88\% yield, 93\% ee).

Substituted Starting Materials. We next studied substituted racemic cyclic starting materials, which can "desymmetrize" the substrates and give rise to diastereomeric intermediates and products. This work probes the scope and limitations of these processes and suggests realistic synthetic applications. We also hoped these studies would shed light on the reaction mechanism, but interpretation is complicated.

Synthesis of allyl chloride $\mathbf{1 5}$ always produced an inseparable mixture of $15 \mathbf{a}$ and $\mathbf{1 5 b}$ in an $\sim 2: 1$ ratio, despite several synthetic approaches. Some enantiomerically enriched methyl substituted allyl chlorides are known, but these are reported to rapidly racemize. ${ }^{82,83}$ During AAA of 15 with 4-phenyl-1butene, regioisomeric products were obtained using stoichiometric nonchiral CuBr.DMS (DMS, dimethyl sulfoxide) as the catalyst (1:1 ratio) or catalytic CuI-A (2:1 ratio), but the ee's of the mixture could not be determined due to their aliphatic nature. Using a single enantiomer ( $>99 \%$ ee) a chiral alkene nucleophile allowed us to determine the "ee" of the products by measuring the diastereotopic ratios of $16 \mathrm{a}$ and $16 \mathrm{~b}$ isomers by NMR spectroscopy. ${ }^{84}$ We obtained $16 \mathbf{a}$ and $16 \mathbf{b}$ in a 5:1 ratio with $51 \%$ "ee" and $18 \%$ "ee" respectively (Scheme $2 \mathrm{a}$, left).

In contrast to $\mathbf{1 5}$, allyl phosphate $\mathbf{1 7}$ could be prepared as a single racemic regioisomer, and optimized conditions gave $\mathrm{S}_{\mathrm{N}} 2 / \mathrm{S}_{\mathrm{N}} 2^{\prime}$ products $16 \mathrm{a}$ and $16 \mathrm{~b}$ in $3: 1$ ratio in favor of $\mathrm{S}_{\mathrm{N}} 2^{\prime}$ with poor enantioselectivity (61\% and $33 \%$ "ee" respectively) (Scheme 2a, right). Overall, these results are difficult to interpret, but these AAA reactions favor formation of the (more hindered) $S_{\mathrm{N}} 2^{\prime}$ product, albeit not with synthetically useful enantioselectivity, and we are uncertain of the structure of the allylic species that actually undergo $\mathrm{C}-\mathrm{C}$ bond formation.

5,5-Disubstituted allyl chloride 18 was found to give 19 with high ee $(86 \%)$ but only low $(30 \%)$ conversion resulting in a very poor yield (19\%), so it appears that bulky disubstitution impairs reactivity (Scheme $2 \mathrm{~b}$ ).

5-Phenyl-substituted allyl chlorides 20, prepared and used as a racemic 4:1 trans/cis diastereomeric mixture, provided a single product, cis-21a, in 66\% yield with $93 \%$ ee (Scheme 2c, left). This result is remarkable, as it shows that, in appropriately
Scheme 2. Cu-Catalyzed AAA of Substituted Allyl Chlorides and Allyl Phosphates ${ }^{a}$

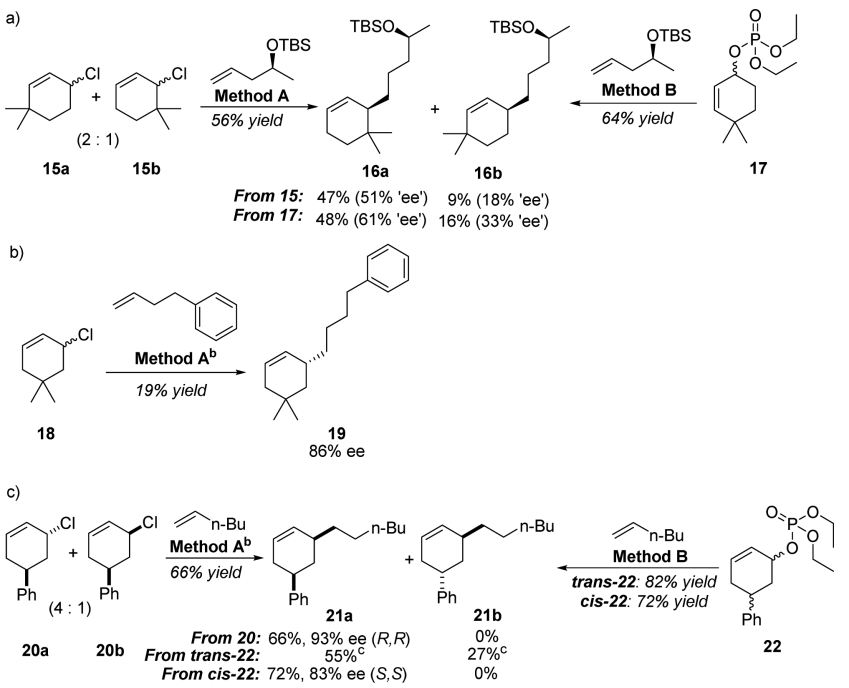

${ }^{a}$ Method A: alkene (2.5 equiv), $\mathrm{Cp}_{2} \mathrm{ZrClH}$ (2.0 equiv), $\mathrm{CH}_{2} \mathrm{Cl}_{2}, \mathrm{CuI}$ (10 mol \%), A (10 mol \%), allyl chloride (1.0 equiv) in $\mathrm{CHCl}_{3}$, room temperature. Method $\mathrm{B}$ : alkene (2.5 equiv), $\mathrm{Cp}_{2} \mathrm{ZrClH}$ (2.0 equiv), $\mathrm{CH}_{2} \mathrm{Cl}_{2}, \mathrm{CuI}(10 \mathrm{~mol} \%), \mathbf{D}(10 \mathrm{~mol} \%)$, allylphosphate (1.0 equiv) TMSCl (1.0 equiv) in $\mathrm{CH}_{2} \mathrm{Cl}_{2}$, room temperature. Isolated yields. Ee was determined by NMR or HPLC. ${ }^{b}$ Prepared using $(R, R, R)-\mathbf{A} .{ }^{c}$ The ee of these products could not be determined due to overlapping signals (see SI, p S113).

designed substrates, a mixture of four isomers (two racemic diastereomers) may be converted into a single diastereomerically and enantiomerically pure product. We speculate that rapid $\mathrm{CuI}-\mathbf{A}$ mediated isomerization of substrates $\mathbf{2 0}$ allows the catalyst to select one isomer of starting material for a highly enantioselective reaction.

5-Phenyl-substituted phosphate $\mathbf{2 2}$ could be isolated as either the trans- or cis-isomer. trans-22a gave a 2:1 ratio of products (Scheme 2c, middle). cis-22b solely gave the cis-product $\mathbf{2 1 a}$ in $72 \%$ yield with $83 \%$ ee (Scheme $2 c$, bottom). These empirical results show divergence in reactivity between the allyl chloride and allyl phosphate substrates.

NMR Studies on AAA Reactions Using Allyl Phosphate 5. In an AAA of allyl phosphate 5 followed by in situ ${ }^{1} \mathrm{H}$ NMR spectroscopy, we observe clean conversion of 5 to product 3 (Figure 6a). 5 was consumed much more rapidly $(<1 \mathrm{~h})$ than product was formed ( $11 \mathrm{~h}$ to completion). We identified allyl chloride $\mathbf{1}$ as an important intermediate. The presence of allyl iodide 2 was also observed, but 2 behaves differently than described above (Figure 2). Here 2 rapidly forms at the beginning of the reaction, reaches a maximum concentration of $\sim 10 \mathrm{~mol} \%$ after $\sim 2 \mathrm{~min}$, and is consumed within $30 \mathrm{~min}$. Signals characteristic of $\mathrm{S}_{\mathrm{N}} 2^{\prime}$ isomerization processes were never observed by in situ EXSYs during this AAA (see SI p S43).

We modeled these kinetics, ${ }^{64}$ assuming AAA preferentially uses allyl chloride $\mathbf{1}$ as a substrate, but some allyl phosphate $\mathbf{5}$ undergoes AAA. The model fits formation of 3 from 1 being 20 times faster $\left(k_{1}=0.042 \mathrm{~mol} \% \cdot \mathrm{min}^{-1}\right)$ (eq 9) than from $\mathbf{5}\left(k_{2}=\right.$ $\left.0.023 \mathrm{~mol} \% \cdot \mathrm{min}^{-1}\right)($ eq 10$)$. We assume TMSCl forms 1 from $5\left(\mathrm{k}_{\mathrm{TMSCl}}=0.212 \mathrm{~mol} \% \cdot \mathrm{min}^{-1}\right)(\mathrm{eq} \mathrm{11})$ and formation of $\mathbf{1}$ is measured to be $\sim 5$ times faster than AAA. This model requires that AAA generates stoichiometric $\mathrm{Cl}^{-}$which reacts with 5 to 


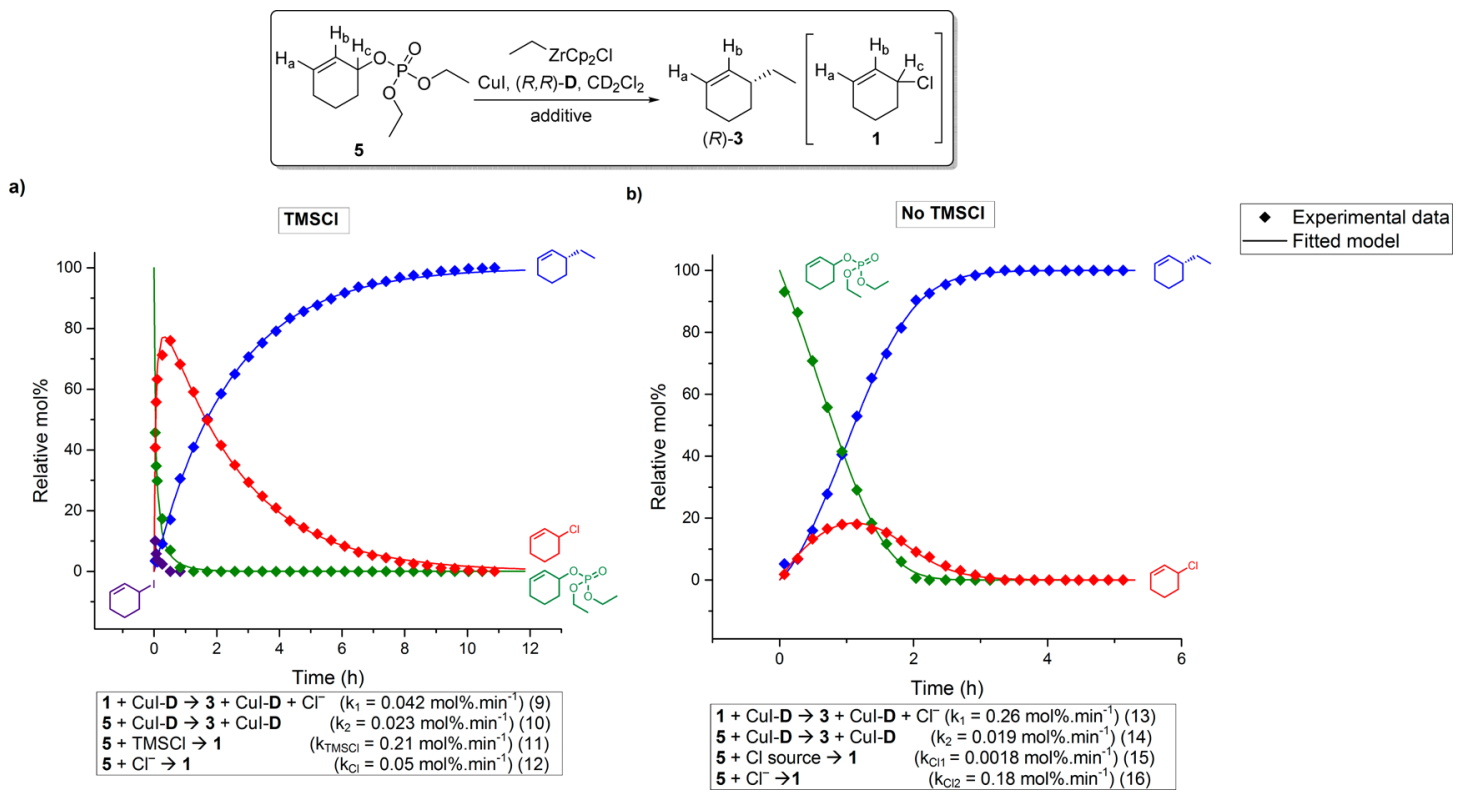

Figure 6. Reaction kinetics of Cu-AAA with allyl phosphate 5 monitored by ${ }^{1} \mathrm{H}$ NMR spectroscopy (a) with TMSCl and (b) without TMSCl and modeled. Conditions: ethylene ( $1 \mathrm{~atm}), \mathrm{Cp}_{2} \mathrm{ZrClH}$ (2.0 equiv) in $\mathrm{CD}_{2} \mathrm{Cl}_{2}, \mathrm{CuI}(10$ allyl iodide), $(R, R)-\mathbf{D}(10$ mol \%), allyl phosphate 5 (1.0 equiv), TMSCl (0 or 1.0 equiv) in $\mathrm{CD}_{2} \mathrm{Cl}_{2}, 298 \mathrm{~K}$. Experimental data recorded by ${ }^{1} \mathrm{H}$ NMR spectroscopy are shown as diamonds. Based on those data points, modeling was performed using Dynafit4 and the resulting fitted curves are shown as solid lines and the input equations, with their rates, below the corresponding graphs.

generate more 1 (eq 12) at a similar rate $\left(k_{\mathrm{Cl}}=0.05 \mathrm{~mol} \%\right.$. $\min ^{-1}$ ) to AAA with 1 .

We also followed AAA with phosphate 5 by in situ ${ }^{31} \mathrm{P}$ NMR spectroscopy. Upon addition of $\mathrm{Cp}_{2} \mathrm{ZrClEt}$ to $\mathrm{CuI}-\mathrm{D}$ in $\mathrm{CD}_{2} \mathrm{Cl}_{2}$ no change was observed. Upon addition of $\mathbf{5}$ and $\mathrm{TMSCl}, \mathbf{5}$ is observed at $-1.5 \mathrm{ppm}$ and a new peak is formed at $9.2 \mathrm{ppm}$ (the phosphate leaving group anion; see SI p S118). At completion, $\left(\mathrm{Et}_{2} \mathrm{O}\right)_{2} \mathrm{P}(\mathrm{O}) \mathrm{O}^{-}$is still present while $\mathbf{5}$ is fully consumed and a variety of new, small, unsymmetrical broad peaks were observed.

Simply adding TMSCl to 5 in $\mathrm{CD}_{2} \mathrm{Cl}_{2}$ shows quantitative formation of 1 in $1 \mathrm{~h}$, but 1 was not observed to isomerize by EXSY. Addition of CuI-D to $\mathbf{5}$ did not result in any observable changes to the ${ }^{1} \mathrm{H}$ or ${ }^{31} \mathrm{P}$ NMR spectra (see SI p S120). So it appears that, contrary to experiments with chloride $\mathbf{1}$, phosphate $\mathbf{5}$ does not directly react with the catalyst to form iodide 2. However, upon addition of TMSCl to a mixture of 5 and CuI-D, allyl phosphate $\mathbf{5}$ is rapidly transformed to allyl chloride $\mathbf{1}$. Allyl iodide $\mathbf{2}$ is also formed and reaches a maximum concentration of $10 \mathrm{~mol} \%$ and is then consumed within $10 \mathrm{~min}$ to give 1. Contrary to experiments carried out on the actual $\mathrm{Cu}$ AAA of $\mathbf{5}$, isomerization of $\mathbf{2}$ was observed by EXSY when $\mathbf{5}$, TMSCl, and CuI-D are mixed in $\mathrm{CD}_{2} \mathrm{Cl}_{2}$.

Upon mixing $\mathrm{Cp}_{2} \mathrm{ZrClEt}$ and $\mathbf{5}$ in $\mathrm{CD}_{2} \mathrm{Cl}_{2}$, the ${ }^{1} \mathrm{H}$ and ${ }^{31} \mathrm{P}$ NMR spectra of 5 remain unaffected, and addition of TMSCl forms 1. Under these conditions formation of 1 reaches completion in $150 \mathrm{~min}, \sim 2.5$ times slower than without $\mathrm{Cp}_{2} \mathrm{ZrClEt}$. In the presence of $\mathrm{Cp}_{2} \mathrm{ZrClEt}$ and TMSCl, 1 is not observed to undergo $S_{\mathrm{N}} 2^{\prime}$ isomerization by EXSY. Overall, 1 seems to originate from addition of $\mathrm{TMSCl}$, but its rate of formation is affected by other reaction components.

We became curious about the mechanism of AAA with 5 in the absence of TMSCl (Figure 5b, entry 6). Using in situ ${ }^{1} \mathrm{H}$ NMR spectroscopy, and the same conditions as above but without $\mathrm{TMSCl}$, we surprisingly observed that this reaction also proceeds through allyl chloride $\mathbf{1}$ (Figure $6 \mathrm{~b}$ ). Allyl iodide 2 was also briefly present at a concentration of $<2 \mathrm{~mol} \%$ and consumed within the first $10 \mathrm{~min}$. Here, no isomerization of 2 or $\mathbf{1}$ was observed by EXSY. TMSCl is known to accelerate $\mathrm{Cu}$ catalyzed conjugate addition reactions, but not without some lingering mechanistic ambiguity. ${ }^{85-91}$ In contrast, here the overall reaction is faster in the absence of TMSCl and reaches completion in $3.5 \mathrm{~h}$, as opposed to $11 \mathrm{~h}$ with TMSCl, but both AAAs have similar half-lives $(\sim 1.5 \mathrm{~h})$. However, despite the overall lower rate of reaction, TMSCl facilitates conversion of allyl phosphate $\mathbf{5}$ to allyl chloride 1 . In the absence of TMSCl consumption of $\mathbf{5}$ is slower $(2 \mathrm{~h})$ than in the presence of $\operatorname{TMSCl}(1 \mathrm{~h})$ and 1 reaches a maximum of $20 \mathrm{~mol} \%$ at $1 \mathrm{~h}$ (compared to $75 \mathrm{~mol} \%$ with TMSCl), as 1 presumably gets transformed to 3 , limiting its concentration. ${ }^{31} \mathrm{P}$ NMR spectroscopy of the TMS-free AAA also shows 5 ( $-1.5 \mathrm{ppm})$ is consumed within $\sim 2 \mathrm{~h}$ and many nonsymmetrical broad signals appear in that region within $12 \mathrm{~h}$ (see SI p S120).

In the AAA of $\mathbf{5}$ without TMSCl, a model ${ }^{64}$ fits formation of 3 being 10 times faster from $1\left(k_{1}=0.26 \mathrm{~mol} \% \cdot \mathrm{min}^{-1}\right.$, eq 13$)$ than from $5\left(k_{2}=0.019 \mathrm{~mol} \% \cdot \mathrm{min}^{-1}\right.$, eq 14) and faster than in the presence of TMSCl $\left(k_{1}=0.042 \mathrm{~mol} \% \cdot \mathrm{min}^{-1}\right)$. As $\mathrm{Cp}_{2} \mathrm{ZrClEt}$ and $\mathrm{CH}_{2} \mathrm{Cl}_{2}$ are the only possible initial sources of chloride, we modeled formation of 1 using $\mathrm{Cp}_{2} \mathrm{ZrClEt}$ as the source (eq 15). The formation of $\mathbf{1}$ is very slow $\left(k_{\mathrm{Cl} 1}=0.0018\right.$ mol $\% \cdot \min ^{-1}$ ) (eq 15$)$, but generating 1 from $\mathrm{Cl}^{-}$produced during AAA is fast $\left(k_{\mathrm{Cl} 2}=0.18 \mathrm{~mol} \% \cdot \mathrm{min}^{-1}\right.$; eq 16$)$ and of the same order of magnitude as formation of 3 from 1 .

TMSCl plays a role in the formation of $\mathbf{1}$, and also affects the catalyst. Upon addition of TMSCl to a solution of CuI-D, instantaneous changes are observed in ${ }^{1} \mathrm{H}$ and ${ }^{31} \mathrm{P}$ NMR spectra suggesting formation of two species (see SI p S130). The minor component of the two newly formed species resembles $\mathrm{CuCl}-\mathrm{D}$ complexes, but the major component is unknown and is not observed during AAA of $\mathbf{5}$ in the presence of TMSCl. Curiously these catalytic modifications do not occur in the presence of $\mathrm{Cp}_{2} \mathrm{ZrClR}$. 

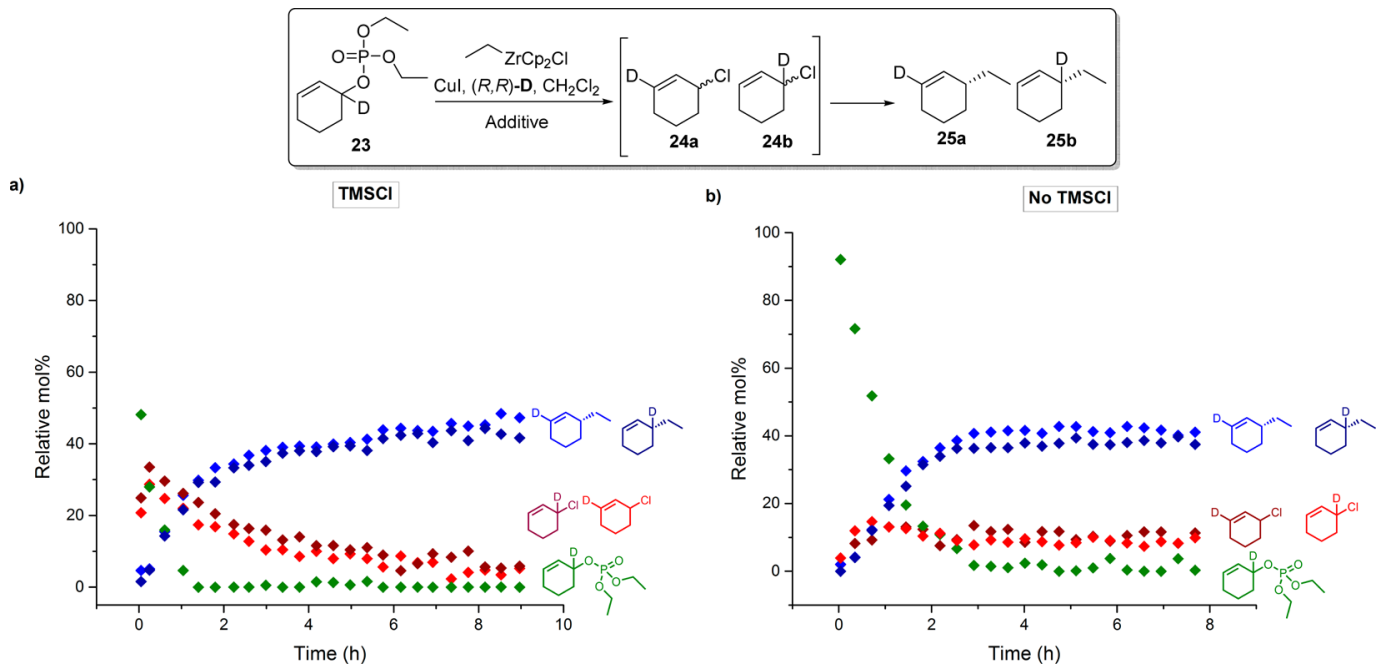

Figure 7. Reaction kinetics of Cu-AAA with d-23 as monitored by ${ }^{2} \mathrm{H}$ NMR spectroscopy (a) with TMSCl and (b) without TMSCl. Conditions: ethylene ( $1 \mathrm{~atm}), \mathrm{Cp}_{2} \mathrm{ZrClH}$ (2.0 equiv) in $\mathrm{CH}_{2} \mathrm{Cl}_{2}, \mathrm{CuI}(10 \mathrm{~mol} \%),(R, R)-\mathbf{D}(10 \mathrm{~mol} \%)$, d-allyl phosphate 23 (1.0 equiv), TMSCl (0 or 1.0 equiv) in $\mathrm{CH}_{2} \mathrm{Cl}_{2}, 298 \mathrm{~K}$.

We also synthesized deuterated allyl phosphate 23. In AAAs with TMSCl monitored by in situ ${ }^{2} \mathrm{H}$ spectroscopy (Figure $7 \mathrm{a}$ ), $\mathrm{d}-\mathbf{2 3}$ is rapidly consumed to form d-allyl chlorides $24 \mathbf{a}$ and $24 \mathbf{b}$ in approximately equal amounts and the d-allyl chlorides in turn form D-products $25 \mathbf{a}$ and $25 \mathbf{b}$ in a 1:1 ratio. ${ }^{2} \mathrm{H}$ NMR spectroscopy on d-23 without TMSCl in situ (Figure 7b) similarly showed that d-23 is consumed slowly to form equal amounts of d-allyl chlorides $\mathbf{2 4 a}$ and $\mathbf{2 4 b}$, which in turn form an $\sim 1: 1$ mixture of $\mathbf{2 5 a}$ and $\mathbf{2 5 b}$.

Adding TMSCl (1.0 equiv) to d-23 (1.0 equiv) shows that it is completely transformed to d-chlorides $\mathbf{2 4 a}$ and $\mathbf{2 4 b}$ within 20 min. Both $S_{N} 2^{\prime}$ and $S_{N} 2$ products are formed, but reaction of 23 with TMSCl appears to prefer $\mathrm{S}_{\mathrm{N}} 2^{\prime}$ pathways (65 mol \% $\beta$ $\mathrm{d}-\mathbf{2 4 a}$ vs $35 \mathrm{~mol} \% \mathbf{2 4 b}$; see SI p S136). As the ratio of $\mathbf{2 4 a}$ and 24b remains largely unchanged under these conditions, d-allyl chlorides 24 appear not to isomerize through $\mathrm{S}_{\mathrm{N}} 2^{\prime}$ mechanisms spontaneously, suggesting that TMSCl alone is not responsible for the 1:1 ratio of $24 a$ and $24 b$ observed during AAA.

We studied the effect of $\mathrm{Cp}_{2} \mathrm{ZrClEt}$ (2.0 equiv) on the formation of $\mathrm{d}-\mathbf{2 4} \mathbf{a}$ and $\mathrm{d}-\mathbf{2 4} \mathbf{b}$ with TMSCl (1.0 equiv). Within $200 \mathrm{~min}, 65 \mathrm{~mol} \%$ of $\mathbf{2 4 b}$ was formed while $35 \mathrm{~mol} \%$ of $24 \mathrm{a}$ was obtained (see SI p S137), so (for reasons that are not understood) addition of $\mathrm{Cp}_{2} \mathrm{ZrClEt}$ appears to reverse the selectivity observed with $\mathrm{TMSCl}$ alone.

We investigated the effect of CuI-D $(10 \mathrm{~mol} \%)$ on the formation of 24a and 24b from d-23. Upon addition of TMSCl, $\mathbf{2 4 a}$ and $\mathbf{2 4 b}$ are formed instantaneously as well as trace amounts of d-allyl iodides (see SI p S137). Here, the D-isomers are formed in equal amount suggesting that $\mathrm{CuI}-\mathrm{D}$ facilitates isomerization of the allyl halide species in the AAA reaction itself.

Finally, we investigated the use of enantiomerically pure allylphosphates (+)-5 and (-)-5 using CuI-D and TMSCl in a reaction to form 4. Although these experiments are difficult because of the very small amount of product formed at early stages of the reaction $(\sim 10 \mathrm{~min})$, no significant difference in the enantiomeric excess of 4 formed from $(-)-,(+)-$, or $( \pm)-5$ was observed (ee values obtained varied from run to run and range from $84 \%$ ee to $93 \%$ ee).

In the AAA of 5, we did not observe the constant presence of allyl iodide $\mathbf{2}$ or see evidence of the $S_{\mathrm{N}} 2^{\prime}$ isomerization of 1 or 2 by EXSY. However, these pathways may still operate at rates undetectable by NMR. It seems likely that, regardless of the source of chloride-1, both CuI-L* catalyzed AAAs with 1 occur via similar mechanisms and that both reactions involve rapidly racemizing starting materials and a DKR type mechanism. But it is not inconceivable that the reaction of phosphate 5 to give $\mathbf{3}$ goes through other pathways.

\section{CONCLUSION}

High yield and enantioselectivity can be achieved in the $\mathrm{Cu}$ catalyzed addition of alkylzirconium reagents to racemic allyl chloride and allyl phosphate electrophiles. Our work suggests a simple but powerful mechanism where CuI-mediated racemization of the starting materials coupled with a highly selective $\mathrm{C}-\mathrm{C}$ bond forming catalyst allows highly enantioselective addition.

A number of different isomerizing agents have been identified potentially facilitating the extension of this strategy to a broader range of reactions. We have also shown that it is possible to quantify the rate of allyl halide isomerization using three different NMR techniques. Here experiments show the rate of $\mathrm{CuI}-\mathrm{A}$ mediated isomerization of allyl iodide 2 is $0.10 \pm$ $0.01 \mathrm{~s}^{-1}$, and kinetic modeling suggests that $\mathbf{1}$ and $\mathbf{2}$ interchange much faster than $\mathrm{C}-\mathrm{C}$ bond formation.

The catalysts involved in $\mathrm{C}-\mathrm{C}$ formation are aggregates of $\mathrm{Cu}$ and phosphoramidite which involve at least two ligands. A critical dependence of the copper counterion was demonstrated, which affects many mechanistic aspects of the reaction. Kinetic modeling suggests that the catalyst is modified during the reaction to contain both $\mathrm{I}$ and $\mathrm{Cl}$ ions and becomes more enantioselective and 3 times faster than the starting catalyst.

A second AAA system was developed using racemic allyl phosphates and new ligand $\mathbf{D}$ which is also an excellent alternative to $\mathbf{A}$ in AAAs with $\mathbf{1}$ and is superior with sevenmembered-ring substrates. Structure-reactivity relationships demonstrated that, in some cases, excellent stereochemical control can be achieved where racemic mixtures of diastereomers are converted to a single diastereoisomer of product with high ee.

AAA reactions with these allyl phosphates, as judged by NMR spectroscopy and isotopic labeling studies, proceed via 
allyl chlorides formed in situ, either by the action of TMSCl or from adventitious $\mathrm{Cl}^{-}$generated from reaction components. The ability to generate rapidly isomerizing allyl halide species in situ from these phosphates is likely to be useful in chemistry far beyond the present studies. We anticipate that this work will aid development of new asymmetric addition reactions using racemic starting materials.

\section{ASSOCIATED CONTENT}

\section{S Supporting Information}

The Supporting Information is available free of charge on the ACS Publications website at DOI: 10.1021/jacs.7b02440.

Experimental procedures, characterization data and relevant NMR spectra (PDF)

\section{AUTHOR INFORMATION}

\section{Corresponding Authors}

*Tim.claridge@chem.ox.ac.uk

*Stephen.fletcher@chem.ox.ac.uk

\section{ORCID}

Timothy D. W. Claridge: 0000-0001-5583-6460

Stephen P. Fletcher: 0000-0001-7629-0997

\section{Notes}

The authors declare no competing financial interest.

\section{ACKNOWLEDGMENTS}

We are grateful to the EPSRC for financial support in the form of a Career Acceleration Fellowship to S.P.F. (EP/H003711/1) and a Standard Grant (EP/N022246/1). The authors acknowledge Dr. Barbara Odell for initial assistance in NMR.

\section{REFERENCES}

(1) Harutyunyan, S.; den Hartog, T.; Geurts, K.; Minnaard, A.; Feringa, B. Chem. Rev. 2008, 108, 2824.

(2) Alexakis, A.; Backvall, J. E.; Krause, N.; Pamies, O.; Dieguez, M. Chem. Rev. 2008, 108, 2796.

(3) Alexakis, A.; Krause, N.; Woodward, S. Copper-Catalyzed Asymmetric Synthesis; Wiley-VCH: Weinheim, 2014.

(4) Harutyunyan, S. Progress in Enantioselective $\mathrm{Cu}(\mathrm{I})$-catalyzed Formation of Stereogenic Centers; Springer: Switzerland, 2016.

(5) Woodward, S. Chem. Soc. Rev. 2000, 29, 393.

(6) Yoshikai, N.; Nakamura, E. Chem. Rev. 2012, 112, 2339.

(7) Trost, B. M.; VanVranken, D. L. Chem. Rev. 1996, 96, 395.

(8) Helmchen, G.; Dahnz, A.; Dubon, P.; Schelwies, M.; Weihofen, R. Chem. Commun. 2007, 675.

(9) Lu, Z.; Ma, S. Angew. Chem., Int. Ed. 2008, 47, 258.

(10) Geurts, K.; Fletcher, S. P.; van Zijl, A. W.; Minnaard, A. J.; Feringa, B. L. Pure Appl. Chem. 2008, 80, 1025.

(11) Hartwig, J. F.; Stanley, L. M. Acc. Chem. Res. 2010, 43, 1461.

(12) Basle, O.; Denicourt-Nowicki, A.; Crevisy, C.; Mauduit, M. In Copper-Catalyzed Asymmetric Synthesis; Alexakis, A., Krause, N., Woodward, S., Eds.; Wiley-VCH: Weinheim, 2014; p 85.

(13) Luchaco-Cullis, C. A.; Mizutani, H.; Murphy, K. E.; Hoveyda, A. H. Angew. Chem., Int. Ed. 2001, 40, 1456.

(14) Piarulli, U.; Daubos, P.; Claverie, C.; Roux, M.; Gennari, C. Angew. Chem., Int. Ed. 2003, 42, 234.

(15) Tissot-Croset, K.; Polet, D.; Alexakis, A. Angew. Chem., Int. Ed. 2004, 43, 2426.

(16) Lee, Y.; Akiyama, K.; Gillingham, D. G.; Brown, M. K.; Hoveyda, A. H. J. Am. Chem. Soc. 2008, 130, 446.

(17) Teichert, J. F.; Zhang, S. Y.; van Zijl, A. W.; Slaa, J. W.; Minnaard, A. J.; Feringa, B. L. Org. Lett. 2010, 12, 4658.
(18) Langlois, J. B.; Alexakis, A. In Transition Metal Catalyzed Enantioselective Allylic Substitution in Organic Synthesis; Kazmaier, U., Ed.; Springer-Verlag Berlin: Berlin, 2012; Vol. 38, p 235.

(19) Backvall, J. E.; Sellen, M.; Grant, B. J. Am. Chem. Soc. 1990, 112, 6615.

(20) Persson, E. S. M.; Vanklaveren, M.; Grove, D. M.; Backvall, J. E.; Vankoten, G. Chem. - Eur. J. 1995, 1, 351.

(21) Norinder, J.; Backvall, J. E.; Yoshikai, N.; Nakamura, E. Organometallics 2006, 25, 2129.

(22) Mori, S.; Nakamura, E. Tetrahedron Lett. 1999, 40, 5319

(23) Yamanaka, M.; Kato, S.; Nakamura, E. J. Am. Chem. Soc. 2004, 126,6287

(24) Yoshikai, N.; Zhang, S. L.; Nakamura, B. J. Am. Chem. Soc. 2008, $130,12862$.

(25) Langlois, J.; Emery, D.; Mareda, J.; Alexakis, A. Chem. Sci. 2012, 3, 1062.

(26) Harutyunyan, S. R.; Lopez, F.; Browne, W. R.; Correa, A.; Pena, D.; Badorrey, R.; Meetsma, A.; Minnaard, A. J.; Feringa, B. L. J. Am. Chem. Soc. 2006, 128, 9103.

(27) von Rekowski, F.; Koch, C.; Gschwind, R. M. J. Am. Chem. Soc. 2014, 136, 11389.

(28) Perez, M.; Fananas-Mastral, M.; Bos, P.; Rudolph, A.; Harutyunyan, S.; Feringa, B. Nat. Chem. 2011, 3, 377.

(29) Fananas-Mastral, M.; Feringa, B. L. J. Am. Chem. Soc. 2010, 132, 13152.

(30) Pineschi, M.; Di Bussolo, V.; Crotti, P. Chirality 2011, 23, 703.

(31) Langlois, J. B.; Alexakis, A. Angew. Chem., Int. Ed. 2011, 50, 1877.

(32) Langlois, J. B.; Alexakis, A. Chem. Commun. 2009, 3868.

(33) Giacomina, F.; Alexakis, A. Eur. J. Org. Chem. 2013, 2013, 6710.

(34) Ito, H.; Kunii, S.; Sawamura, M. Nat. Chem. 2010, 2, 972.

(35) Yasuda, Y.; Ohmiya, H.; Sawamura, M. Angew. Chem., Int. Ed. 2016, 55, 10816.

(36) Gao, Y.; Hanson, R. M.; Klunder, J. M.; Ko, S. Y.; Masamune, H.; Sharpless, K. B. J. Am. Chem. Soc. 1987, 109, 5765.

(37) Tokunaga, M.; Larrow, J. F.; Kakiuchi, F.; Jacobsen, E. N. Science 1997, 277, 936.

(38) Huerta, F. F.; Minidis, A. B. E.; Bäckvall, J. E. Chem. Soc. Rev. 2001, 30, 321.

(39) Faber, K. Chem. - Eur. J. 2001, 7, 5004.

(40) Vedejs, E.; Jure, M. Angew. Chem., Int. Ed. 2005, 44, 3974

(41) Mohr, J. T.; Ebner, D. C.; Stoltz, B. M. Org. Biomol. Chem. 2007, 5,3571 .

(42) Noyori, R.; Tokunaga, M.; Kitamura, M. Bull. Chem. Soc. Jpn. 1995, 68, 36

(43) Pellissier, H. Tetrahedron 2008, 64, 1563.

(44) Pfaltz, A.; Lautens, M. In Comprehensive Asymmetric Catalysis II; Jacobsen, E. N., Pfaltz, A., Yamamoto, H., Eds.; Springer-Verlag: Berlin, 1999; Vol. 2, p 833.

(45) Trost, B. M. Chem. Pharm. Bull. 2002, 50, 1.

(46) Trost, B. M.; Crawley, M. L. Chem. Rev. 2003, 103, 2921.

(47) Norinder, J.; Bogar, K.; Kanupp, L.; Backvall, J. E. Org. Lett. 2007, 9, 5095.

(48) Norinder, J.; Backvall, J. E. Chem. - Eur. J. 2007, 13, 4094.

(49) Heaton, B. Mechanisms in Homogeneous Catalysis: A Spectroscopic Approach; Wiley: 2006.

(50) Gschwind, R. M. Chem. Rev. 2008, 108, 3029.

(51) Pregosin, P. S. NMR in Organometallic Chemistry; John Wiley \& Sons: 2012.

(52) Brown, J. M. Organometallics 2014, 33, 5912.

(53) Claridge, T. D. W. High-Resolution NMR Techniques in Organic Chemistry, 3rd ed.; Elsevier Science: 2016.

(54) Nakamura, E.; Yamanaka, M.; Mori, S. J. Am. Chem. Soc. 2000, $122,1826$.

(55) Bertz, S. H.; Cope, S.; Murphy, M.; Ogle, C. A.; Taylor, B. J. J. Am. Chem. Soc. 2007, 129, 7208.

(56) Bertz, S. H.; Murphy, M. D.; Ogle, C. A.; Thomas, A. A. Chem. Commun. 2010, 46, 1255. 
(57) Zhang, H.; Gschwind, R. M. Angew. Chem., Int. Ed. 2006, 45, 6391

(58) Zhang, H.; Gschwind, R. M. Chem. - Eur. J. 2007, 13, 6691.

(59) Zhang, H.; Kerssebaum, R.; Gschwind, R. M. Magn. Reson. Chem. 2009, 47, 568.

(60) von Rekowski, F.; Gschwind, R. M. Organometallics 2014, 33, 6259.

(61) You, H.; Rideau, E.; Sidera, M.; Fletcher, S. P. Nature 2015, 517, 351.

(62) We note that due to the presence of $\mathrm{Cu}$, the benzylic signal of $\mathrm{Cu}-\mathrm{A}$ complexes is always observed as a broad singlet instead of the expected two overlapping quartets observed in the free ligand $\mathbf{A}$.

(63) Rideau, E.; Fletcher, S. P. Beilstein J. Org. Chem. 2015, 11, 2435.

(64) $k$ rate constants were obtained by fitting of a binding model by nonlinear least-squares regression using the DynaFit 4 software package: Kuzmič, P. Anal. Biochem. 1996, 237, 260.

(65) Jerphagnon, T.; Pizzuti, M.; Minnaard, A.; Feringa, B. Chem. Soc. Rev. 2009, 38, 1039.

(66) Schober, K.; Hartmann, E.; Zhang, H.; Gschwind, R. M. Angew. Chem., Int. Ed. 2010, 49, 2794.

(67) Evans, R.; Deng, Z.; Rogerson, A. K.; McLachlan, A. S.; Richards, J. J.; Nilsson, M.; Morris, G. A. Angew. Chem., Int. Ed. 2013, 52, 3199.

(68) Oliva, A. I.; Gomez, K.; Gonzalez, G.; Ballester, P. New J. Chem. 2008, 32, 2159.

(69) Sprafke, J. K.; Odell, B.; Claridge, T. D. W.; Anderson, H. L. Angew. Chem., Int. Ed. 2011, 50, 5572.

(70) Hutin, M.; Sprafke, J. K.; Odell, B.; Anderson, H. L.; Claridge,

T. D. W. J. Am. Chem. Soc. 2013, 135, 12798.

(71) Jerschow, A.; Muller, N. J. Magn. Reson. 1997, 125, 372.

(72) Jerschow, A.; Muller, N. J. Magn. Reson. 1998, 132, 13.

(73) Girard, C.; Kagan, H. B. Angew. Chem., Int. Ed. 1998, 37, 2923.

(74) Kagan, H. B. Adv. Synth. Catal. 2001, 343, 227.

(75) Kagan, H. B. Synlett 2001, 2001, 888.

(76) Aski, S. N.; Takacs, Z.; Kowalewski, J. Magn. Reson. Chem. 2008, 46, 1135.

(77) Sippl, S. P.; White, P. B.; Fry, C. G.; Volk, S. E.; Ye, L.; Schenck, H. L. Magn. Reson. Chem. 2016, 54, 46.

(78) Bain, A. D.; Cramer, J. A. J. Magn. Reson., Ser. A 1996, 118, 21.

(79) Bain, A. D. Prog. Nucl. Magn. Reson. Spectrosc. 2003, 43, 63.

(80) Bain, A. D. Annu. Rep. NMR Spectrosc. 2008, 63, 23.

(81) Quiros, M. T.; Angulo, J.; Munoz, M. P. Chem. Commun. 2015, $51,10222$.

(82) Goering, H. L.; Nevitt, T. D.; Silversmith, E. F. J. Am. Chem. Soc. 1955, 77, 4042 .

(83) Lesnini, D. G.; Buckley, P. D.; Noyes, R. M. J. Am. Chem. Soc. 1968, 90, 668.

(84) Sidera, M.; Fletcher, S. P. Chem. Commun. 2015, 51, 5044.

(85) Corey, E. J.; Boaz, N. W. Tetrahedron Lett. 1985, 26, 6015.

(86) Corey, E. J.; Boaz, N. W. Tetrahedron Lett. 1985, 26, 6019.

(87) Alexakis, A.; Berlan, J.; Besace, Y. Tetrahedron Lett. 1986, 27, 1047.

(88) Nakamura, E.; Matsuzawa, S.; Horiguchi, Y.; Kuwajima, I. Tetrahedron Lett. 1986, 27, 4029.

(89) Corey, E. J.; Hannon, F. J.; Boaz, N. W. Tetrahedron 1989, 45, 545.

(90) Alexakis, A.; Sedrani, R.; Mangeney, P. Tetrahedron Lett. 1990, 31,345 .

(91) Lipshutz, B. H.; Dimock, S. H.; James, B. J. Am. Chem. Soc. 1993, 115, 9283. 